\title{
The value of writing skills as an addition to the medical school curriculum
}

This article was published in the following Dove Press journal:

Advances in Medical Education and Practice

26 July 2017

Number of times this article has been viewed

\section{Bassit Malik}

School of Medicine, Imperial College London, London, UK
Correspondence: Bassit Malik School of Medicine, Imperial College London, London SW7 2AZ, UK

Tel +4477 69688248

Email Bassit.Malik12@imperial.ac.uk
The Medical Schools Council statement lists the ability to communicate through reading, writing, listening, and speaking as four skills all medical students should possess as future doctors. ${ }^{1}$

First and foremost, writing in a legible manner is imperative for good clinical practice and poor prescribing and documenting can have harmful consequences for the patient. ${ }^{1}$ The ability to write effectively is also an important medium in conveying complex scientific concepts and critical clinical information.

Academic entry into UK medical school relies upon competency in the English language, with some institutions requiring grade A in GCSE English. ${ }^{2}$ While additional medical aptitude tests may assess the communication of scientific concepts ${ }^{3}$ in a succinct and articulate manner, examinations in the early years of medical school rely heavily on multiple choice questions, with little room for essay-based questions. Thus, the significance of effective communication and the ability to captivate an audience may only be appreciated in later years of medical education.

Undertaking a BSc alongside medical studies develops some skills in scientific writing and presentation, which are tested in the formal compilation of the dissertation. It is, however, naive to assume that writing skills can be perfected during this time. Students learn how to reflect upon the audience, who will engage with their research, but this is often comprised heavily by an academic body of experts.

It can be argued that medical writing should be more than just an academic exercise for medical students. It should in fact be a means of translating scientific research into policies, outcomes, and health messages that positively affect patient care and most importantly are understood by the patient.

Patients in the 21 st century can access a wealth of health information at the tap of a button. This suggests a greater need for medical students to hone in on the skill of written communication. Although writing skills evolve with guidance and feedback, dedicated formal courses offering training in medical writing skills are somewhat sparse. With a dedicated verbal communication curriculum focused on the doctorpatient relationship, already established in undergraduate medical education, ${ }^{4}$ one could foresee a valuable opportunity for an addition to the curriculum, with written communication. Better written communication can help patients understand their condition and thereby empower them to make more informed decisions regarding their care. ${ }^{5}$ We see this new teaching opportunity and the skills learned from it, as valuable for many aspects of the medical career and of great benefit for patients. 


\section{Disclosure}

The author reports no conflicts of interest in this work.

\section{References}

1. Medical Schools Council. Statement on the Core Values and Attributes Needed to Study Medicine. Medical Schools Council; 2014. Available from: http://www.medschools.ac.uk/SiteCollectionDocuments/ Statement-on-core-values-and-attributes.pdf. Accessed May 24, 2017.

2. Medical Schools Council. Entry Requirements for UK Medical Schools. 2017 Entry. Medical Schools Council; 2016. Available from: http://www. medschools.ac.uk/SiteCollectionDocuments/MSC-Entry-requirementsfor-UK-medical-schools.pdf. Accessed May 24, 2017.
3. Cambridge English Language Assessment. Biomedical Admissions Test (BMAT) Test Specification. Admissions Testing Service; 2016. Available from: http://www.admissionstestingservice.org/images/47829-bmat-testspecification.pdf. Accessed May 24, 2017.

4. von Fragstein M, Silverman J, Cushing A, et al; UK Council for Clinical Communication Skills Teaching in Undergraduate Medical Education. UK consensus statement on the content of communication curricula in undergraduate medical education. Med Educ. 2008;42(11): $1100-1107$.

5. European Patients Forum. EPF Background Brief: Patient Empowerment. European Patients Forum; 2015. Available from: http://www. eu-patient.eu/globalassets/campaign-patient-empowerment/briefing_paperpatient-empowerment_final_external.pdf. Accessed May 24, 2017.

\section{Publish your work in this journal}

Advances in Medical Education and Practice is an international, peerreviewed, open access journal that aims to present and publish research on Medical Education covering medical, dental, nursing and allied health care professional education. The journal covers undergraduate education, postgraduate training and continuing medical education including emerging trends and innovative models linking education, research, and health care services. The manuscript management system is completely online and includes a very quick and fair peer-review system. Visit http://www.dovepress.com/testimonials.php to read real quotes from published authors.

Submit your manuscript here: http://www.dovepress.com/advances-in-medical-education-and-practice-journal 